\title{
Prognostic value of diffuse versus intestinal histotype in patients with gastric cancer: a systematic review and meta-analysis
}

\author{
Fausto Petrelli ${ }^{1}$, Rosa Berenato ${ }^{2}$, Luca Turati ${ }^{3}$, Alessia Mennitto ${ }^{2}$, Francesca Steccanella ${ }^{3}$, Marta \\ Caporale $^{2}$, Pierpaolo Dallera ${ }^{3}$, Filippo de Braud ${ }^{2}$, Ezio Pezzica ${ }^{4}$, Maria Di Bartolomeo ${ }^{2}$, Giovanni Sgroi ${ }^{3}$, \\ Vincenzo Mazzaferro $^{5}$, Filippo Pietrantonio ${ }^{2}$, Sandro Barni ${ }^{1}$ \\ ${ }^{1}$ Medical Oncology Unit, Oncology Department, ASST Bergamo Ovest, Treviglio (BG), Italy; ${ }^{2}$ Medical Oncology Department, Fondazione IRCCS \\ Istituto Nazionale dei Tumori, Milan, Italy; ${ }^{3}$ Surgical Oncology Unit, Surgery Department, ${ }^{4}$ Pathology Unit, Oncology Department, ASST Bergamo \\ Ovest, Treviglio (BG), Italy; ${ }^{5}$ Hepatobiliopancreatic Surgery Unit, Fondazione IRCCS Istituto Nazionale dei Tumori, Milan, Italy \\ Contributions: (I) Conception and design: All authors; (II) Administrative support: All authors; (III) Provision of study materials or patients: All \\ authors; (IV) Collection and assembly of data: All authors; (V) Data analysis and interpretation: All authors; (VI) Manuscript writing: All authors; (VII) \\ Final approval of manuscript: All authors. \\ Correspondence to: Dr. Fausto Petrelli. ASST Bergamo Ovest; 24047 Treviglio (BG), Italy. Email: faupe@libero.it.
}

\begin{abstract}
Background: There are two distinct types of gastric carcinoma (GC), intestinal, more frequently sporadic and linked to environmental factors, and diffuse (undifferentiated) that is highly metastatic and characterized by rapid disease progression and a poor prognosis. However, there are many conflicting data in the literature concerning the association between histology and prognosis in GC. This meta-analysis was performed to provide demonstration if histology according to Lauren classification is associated with different prognosis in patients with GC.

Methods: We searched PubMed, the Cochrane Library, SCOPUS, Web of Science, CINAHL, and EMBASE for all eligible studies. The combined hazard ratios (HRs) and their corresponding 95\% confidence intervals (CIs) in terms of overall survival (OS) were evaluated.

Results: A total of 73 published studies including 61,468 patients with GC were included in this meta-analysis. Our analysis indicates that GC patients with diffuse-type histology have a worst prognosis than those with intestinal subgroup in all studies (HR 1.23; 95\% CI, 1.17-1.29; $\mathrm{P}<0.0001$ ), in both loco-regional confined (HR 1.21; 95\% CI, 1.12-1.30; $\mathrm{P}<0.0001$ ) and advanced disease (HR 1.25; 95\% CI, 1.046-1.50; $\mathrm{P}=0.014$ ), in Asiatic (HR 1.2; 95\% CI, 1.14-1.27; P<0.0001) and Western patients (HR 1.3; 95\% CI, 1.19-1.41; $\mathrm{P}<0.0001$ ), and in those not exposed (HR 1.15; 95\% CI, 1.07-1.24; $\mathrm{P}<0.0001$ ) or exposed (HR 1.27; 95\% CI, $1.17-1.37 ; \mathrm{P}<0.0001$ ) to (neo)adjuvant therapy.

Conclusions: Our results indicated that histology might be a useful prognostic marker for both early and advanced GC patients, with intestinal-type associated with a better outcome. This information could be used for stratification purpose in future clinical trials.
\end{abstract}

Keywords: Gastric cancer (GC); prognostic factor; Lauren classification; diffuse histology; meta-analysis

Submitted Oct 06, 2016. Accepted for publication Nov 23, 2016.

doi: 10.21037/jgo.2017.01.10

View this article at: http://dx.doi.org/10.21037/jgo.2017.01.10

\section{Introduction}

Despite its incidence in Western countries had a steady decline over the last decade, gastric cancer (GC) still represents one of the major causes of cancer mortality worldwide (1). The prognosis of GC is mostly related to disease extension according to the seventh TNM classification (2). Currently, the clinical or pathological stage is the only validated tool available in the clinical practice to drive treatment decision-making. However, it 
must be pointed out that the individual risk of recurrence significantly varies within the same stage, and overall survival (OS) profoundly depends on additional prognostic factors $(3,4)$.

The diffuse and intestinal types of GC describe two histological entities that are different with regard to epidemiology, pathogenesis, biological features and clinical behavior. Currently, there is no difference in the clinical management of these two main histotypes identified by both World Health Organization and Lauren's classification systems $(5,6)$. It is generally recognized that GC with a differentiated histology or intestinal-type shows a better prognosis than individual with a poorly differentiated histology or a diffuse-type (7). However, most available studies were limited by the small sample size and retrospective nature, with consequent methodological limitations and barriers in validating the histotype as an independent prognostic factor.

In this systematic review and meta-analysis, we aimed at clarifying the prognostic value of Lauren's classification in patients with surgically resected GC.

\section{Methods}

\section{Search strategy}

The search was performed searching the electronic database PubMed, the Cochrane Library, SCOPUS, Web of Science, EMBASE and CINAHL up to December 2015. Searches included the terms ("gastric cancer" or "gastric carcinoma") and ("Lauren" or intestinal or diffuse) and (multivariate or multivariable or cox regression) and (hazard ratio). Manual selection of relevant studies was carried out based also on the related articles function. The citation lists of all retrieved articles were analyzed to identify other potentially relevant reports.

\section{Study selection and data extraction}

The following criteria for eligibility among studies were set before collecting articles: (I) histology according to Lauren classification was evaluated in primary GC tissue (biopsies or surgical specimen of primary tumor); (II) survival information (median OS) at specific follow-up was reported in the article as HR according to multivariate analysis, after histology classification resulted significantly in univariate analysis; (III) articles were published in English language; (IV) when several articles were published by the same authors or group, the newest or most informative single article was selected. Exclusion criteria were the following: (I) no information on OS was provided; (II) letters to editor/commentary, reviews, and articles published in a book or papers; (III) clinical studies with chemotherapy or concurrent chemoradiotherapy treatment investigating response rates only.

Two authors (FaP and RB) did the search and identification independently, and selection of an article was reached by consensus with a third author (FiP). The following information was extracted from each report by the two authors independently: year of publication, country, patient size, type of study, histology (intestinal vs. diffuse disease rates), disease stage (locoregional tumors vs. stage IV), surgery (rate), type and rate of (neo)adjuvant therapy, survival data (HRs) and covariates indagates in multivariate analysis.

\section{Statistical analysis}

For analysis of survival results, HRs were pooled to provide an aggregate value. In this analysis, all HRs with 95\% confidence intervals (CIs) adjusted for the maximum number of covariates (significantly associated with OS in univariate analysis) and available in the articles, were combined for obtaining a prognostic information of diffuse ( $v s$. intestinal) histology, independent of other clinicopathological covariates. Subgroup analysis was performed according to race (Asiatic vs. non-Asiatic origin, localized $v s$. stage IV disease, and no systemic therapy $v s$. systemic therapy exposure). Data were entered into the Comprehensive Meta Analysis software v 3.3.070

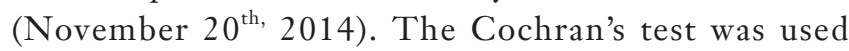
to assess the heterogeneity of included studies. For heterogeneity tests, $\mathrm{P}<0.05$ was considered to indicate significance. If the test of heterogeneity was significant $\left(\mathrm{P}<0.05\right.$ or $\left.\mathrm{I}^{2}>50 \%\right)$, the random-effect model was used. Otherwise, the fixed-effect model was used. By convention, an observed HR of $>1$ implied the worst survival for the group with diffuse histology.

We finally investigated publication bias for OS metaanalysis with a visual inspection of funnel plots and with the Begg-Mazumdar Kendall's tau and Egger's bias test $(8,9)$. Moreover, in the presence of publication bias for the primary analyses, we conducted a trim-and-fill-adjusted analysis (10) to remove the most extreme small studies from the positive side of the funnel plot, and recalculated the effect size at each iteration, until the funnel plot was 


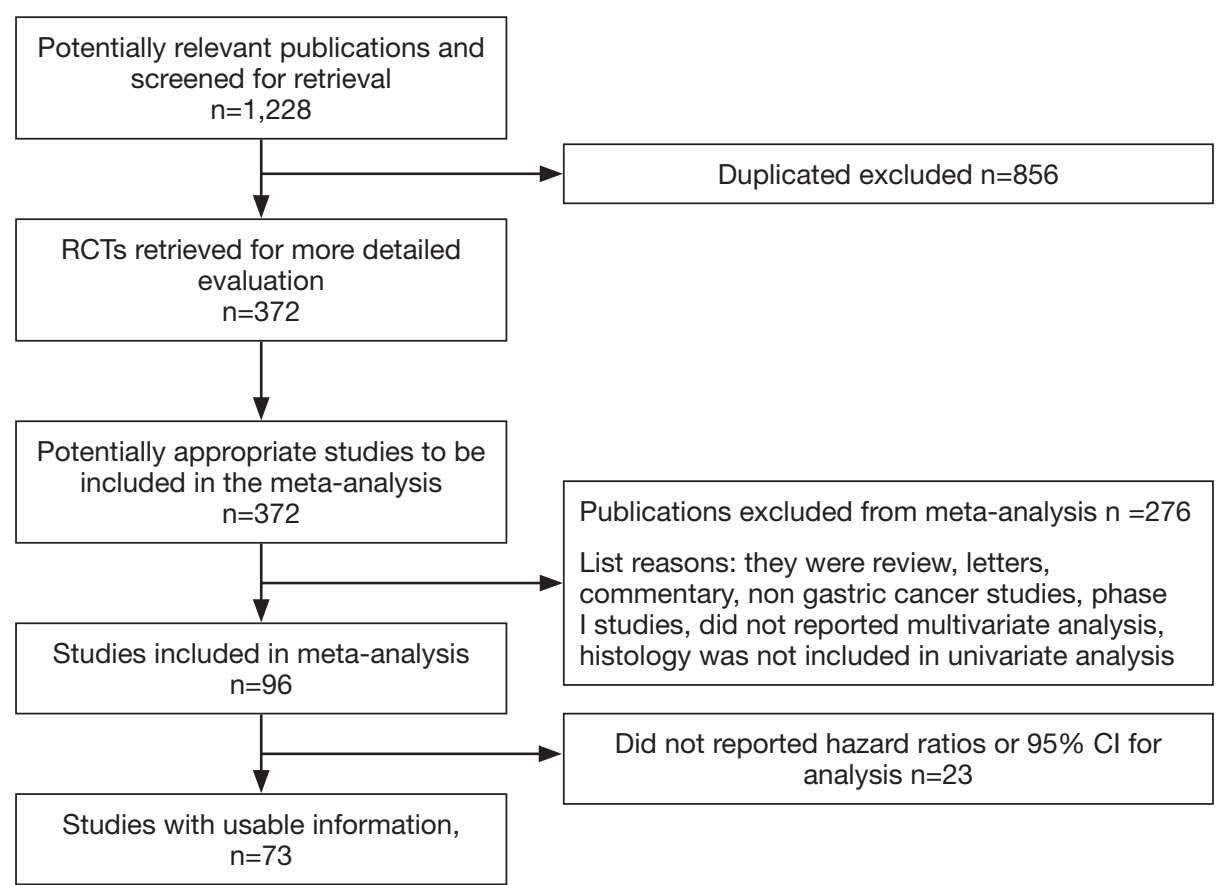

Figure 1 Overview of trials search and selection.

symmetric about the (new) effect size.

\section{Results}

A total of 1,228 potentially relevant citations were reviewed (Figure 1). Among them, 23 reported OS data as risk ratio or odds ratio or did not report $95 \% \mathrm{CI}$ for inclusion in the final analysis. Ultimately, 73 studies (Table 1) that reported the prognostic value of histology classification for OS were analyzed. The total number of patients included was 61,468 , ranging from 41 to 11,189 patients per study (median, 274). The major characteristics are shown in Table 1.

In $\mathrm{n}=7$ publications a retrospective analysis of prospective trials was presented, all other publications reported a retrospective analysis of surgically treated series of patients with GC. The majority $(\mathrm{n}=45)$ were Asiatic countries publications; the remaining $\mathrm{n}=28$ publication were of Western origin (including $n=3$ multinational, $n=5$ US, $n=1$ Brazilian, $n=16$ European, $n=1$ Giordany, $n=1$ Tunisian and $n=1$ Turkish series). Surgery of the primary tumor was performed in all patients in $\mathrm{n}=68$ studies. Chemotherapy, plus or minus radiotherapy was offered to many patients except in $\mathrm{n}=20$ publication where no patients received systemic therapy (in $\mathrm{n}=18$ studies this data was not reported). When reported, intestinal histology ranged from $8.5 \%$ to $83 \%$ of patients, diffuse subtype from $9.8 \%$ to $73.5 \%$ (only in $\mathrm{n}=6$ studies rates of different histologies were not reported).

\section{Meta-analysis of adjusted hazard ratios (HRs) for OS (all studies)}

The effect of histology classification on OS was evaluated in all studies with a total of 61,468 patients analyzed. Overall, the HRs of each study (adjusted for the maximum number of the covariates available and with significant association in univariate analysis) were pooled using a random-effect model, and the final value (HR 1.23; 95\% CI, 1.17-1.29; $\mathrm{P}<0.0001 ; \mathrm{I}^{2} 38 \%$, P for heterogeneity 0.001; Figure 2), indicates that diffuse histology was an indicator of worst prognosis.

\section{Subgroup analysis according to race, stage and systemic therapy}

In studies selected for the country (Asiatic $v s$. non-Asiatic countries, only $n=2$ studies not included for mixed origins) the increased risk of death associated with diffuse histology was similar (HR 1.22; 95\% CI, 1.15-1.29; $\mathrm{P}<0.0001$ vs. HR $1.28 ; 95 \% \mathrm{CI}, 1.19-1.38 ; \mathrm{P}<0.0001$ according to random 


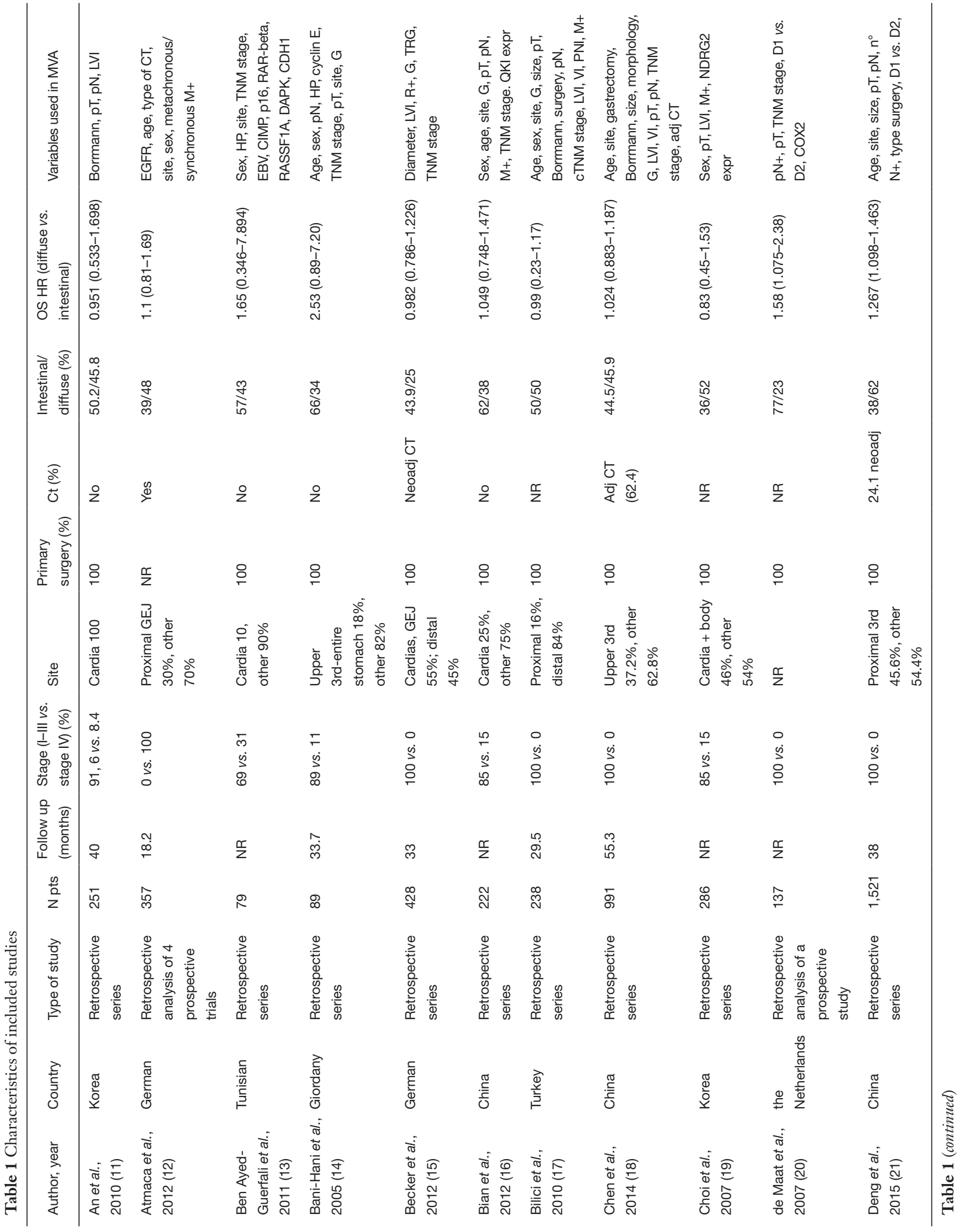




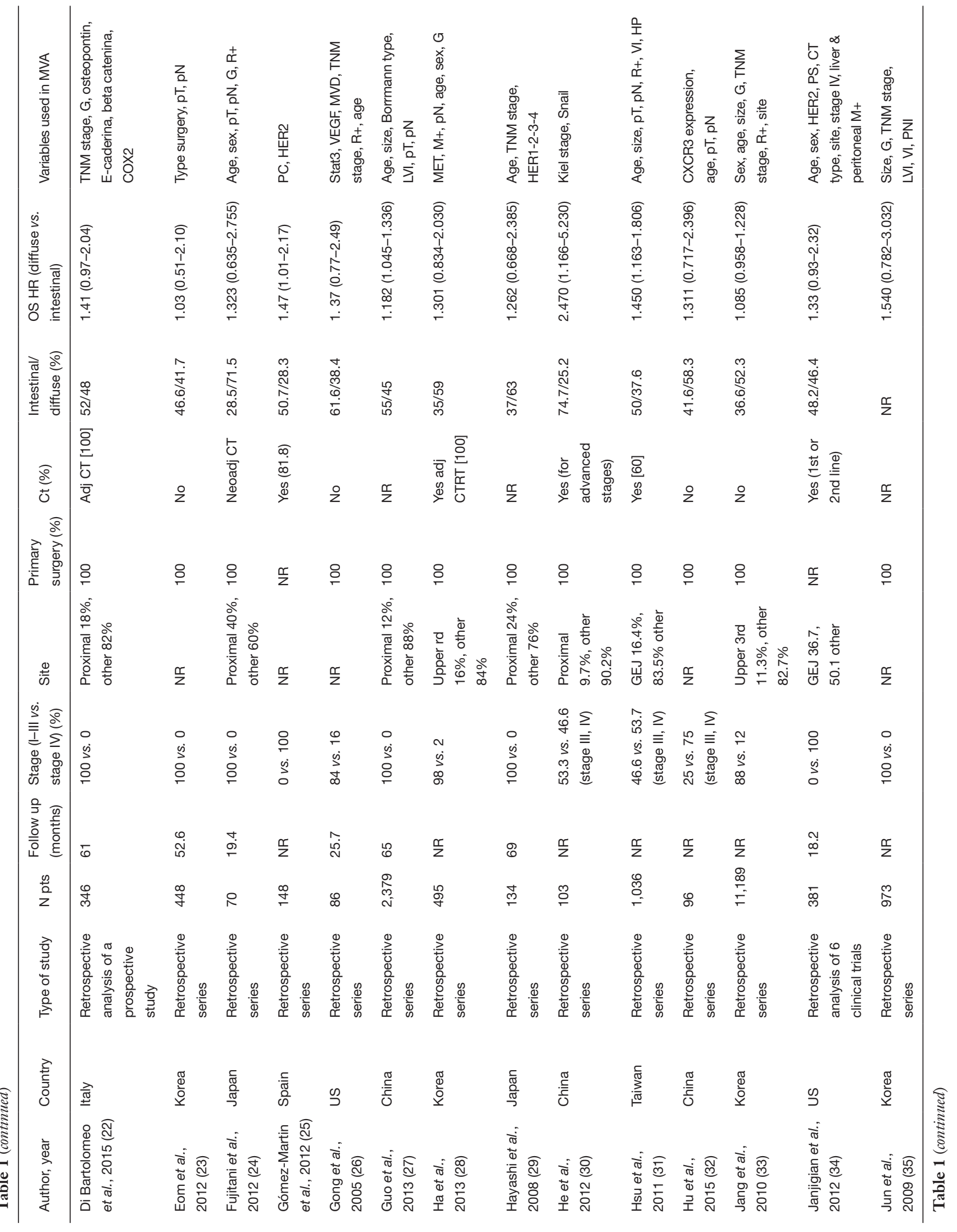




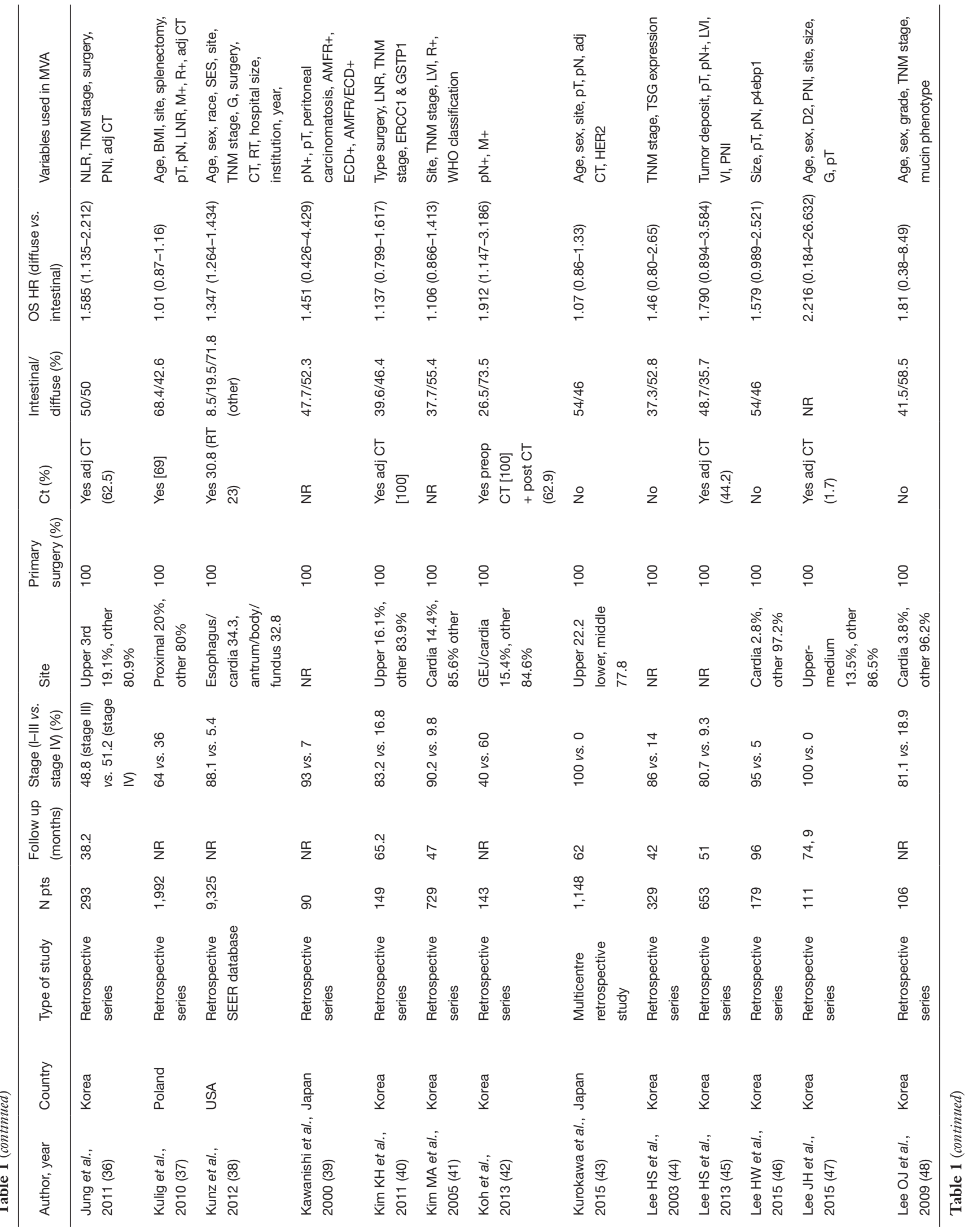




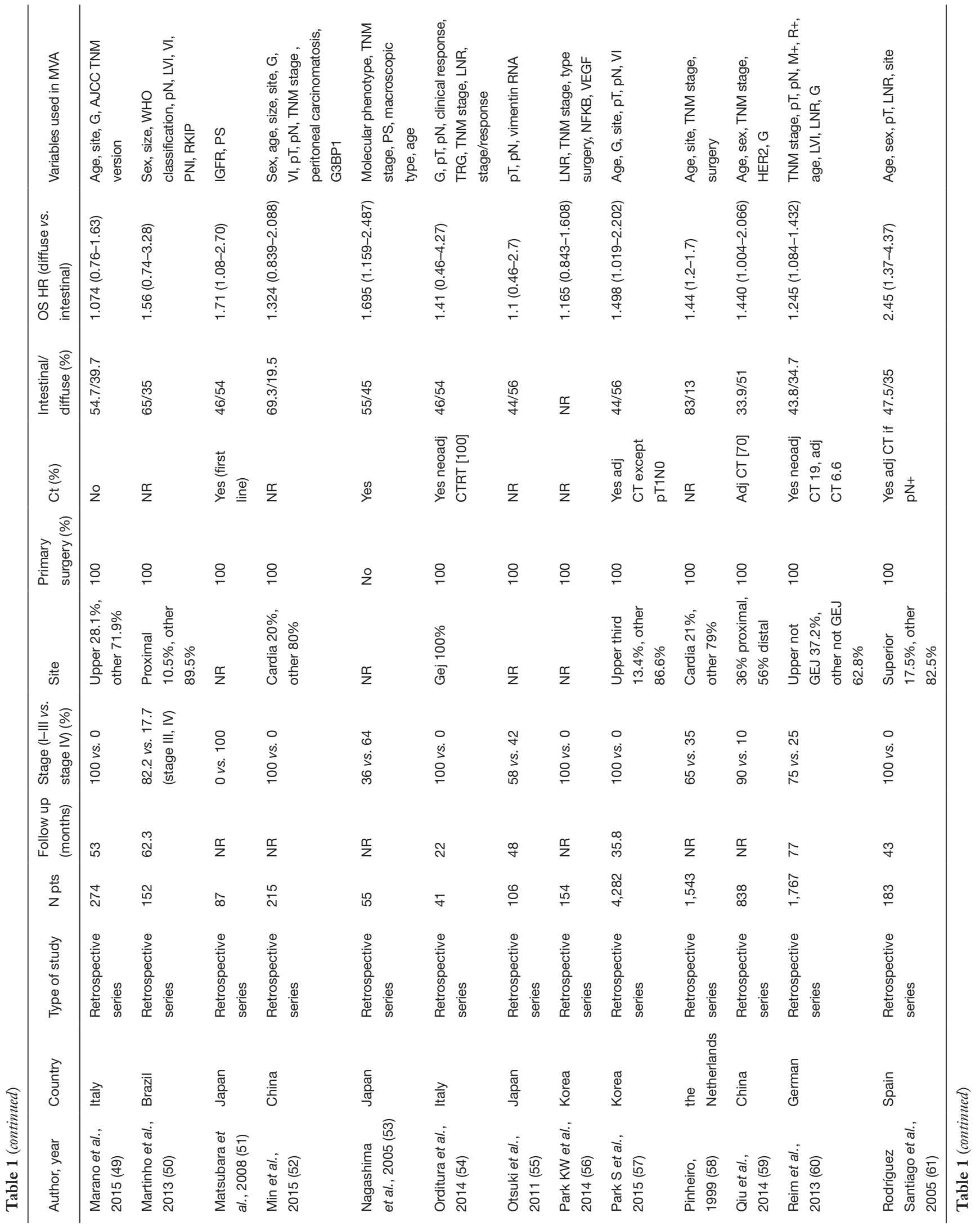




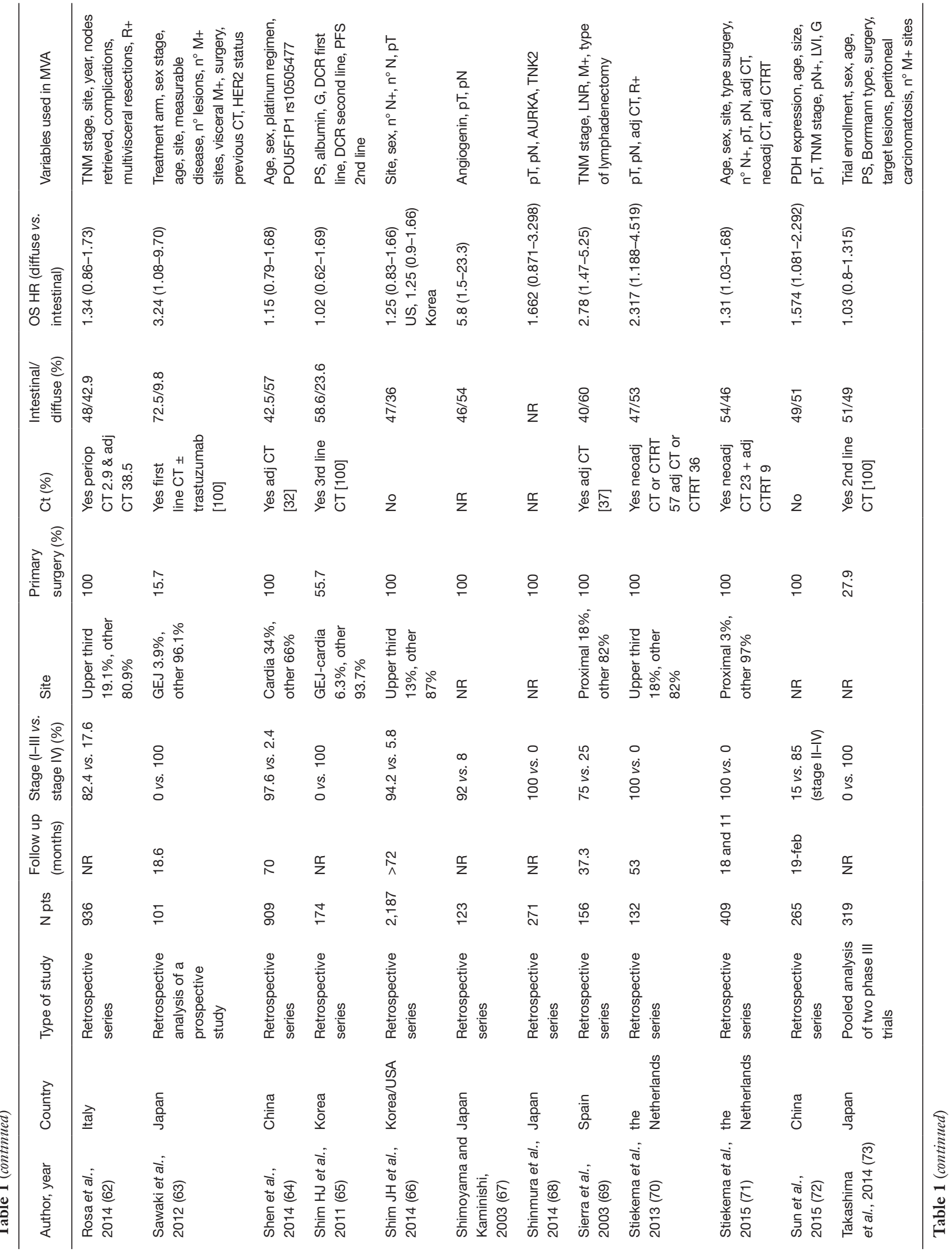




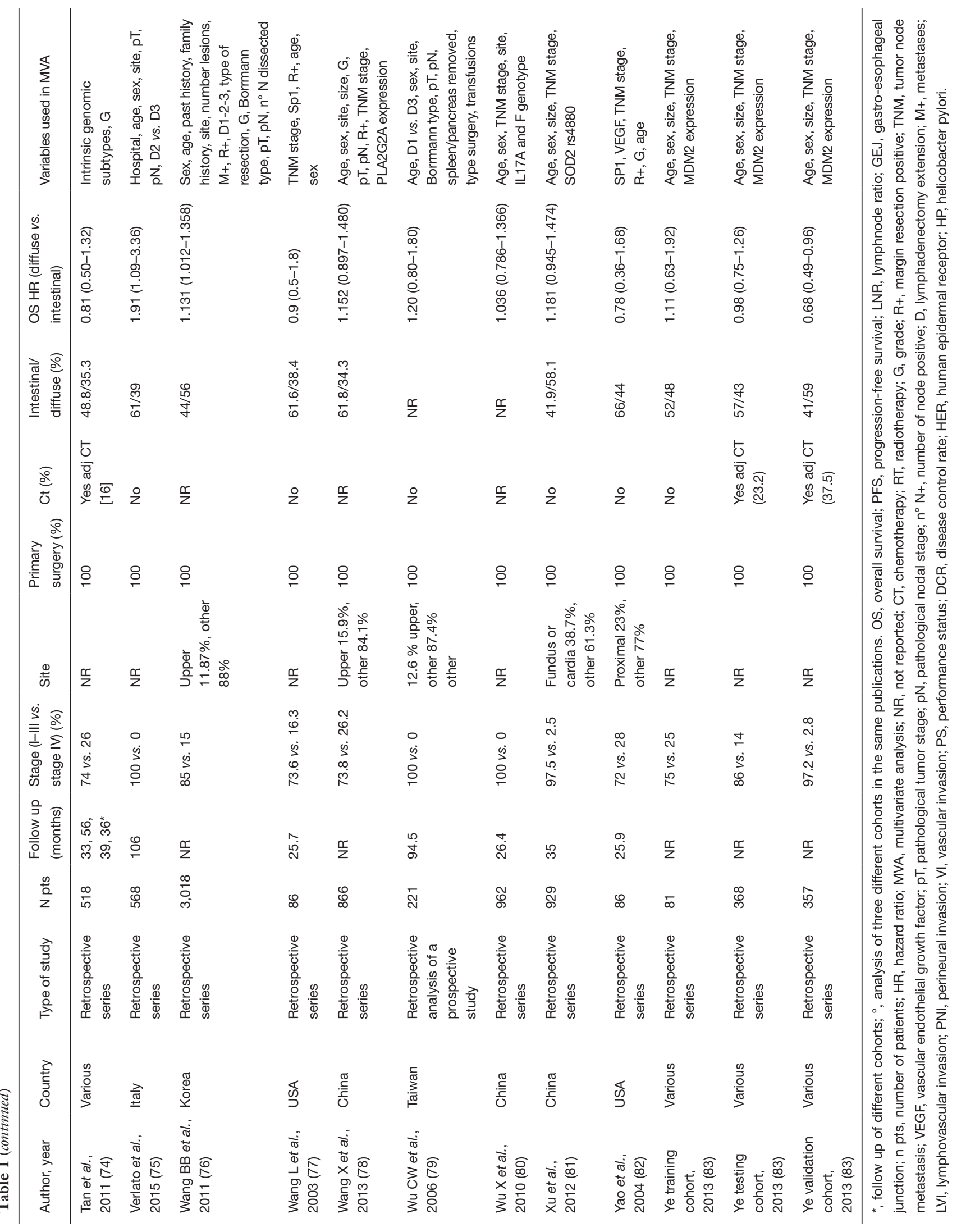




\begin{tabular}{|c|c|c|c|c|c|c|}
\hline \multirow[t]{2}{*}{ Studyname } & \multirow[t]{2}{*}{ Country } & \multirow[b]{2}{*}{$\begin{array}{c}\text { Hazard } \\
\text { ratio }\end{array}$} & \multicolumn{3}{|c|}{ Statistics for each study } & \multirow[b]{2}{*}{ p-Value } \\
\hline & & & $\begin{array}{l}\text { Lower } \\
\text { limit }\end{array}$ & $\begin{array}{l}\text { Upper } \\
\text { limit }\end{array}$ & Z-Value & \\
\hline An 2010 & Korea & 0,951 & 0,533 & 1,697 & $-0,170$ & 0,865 \\
\hline Atmaca 2012 & German & 1,100 & 0,810 & 1,494 & 0,610 & 0,542 \\
\hline Ayed-Guerfali 2011 & Tunisian & 1,650 & 0,346 & 7,868 & 0,628 & 0,530 \\
\hline Bani-Hani 2005 & Gordany & 2,530 & 0,890 & 7,192 & 1,741 & 0,082 \\
\hline Becker 2012 & Geman & 0,982 & 0,786 & 1,227 & $-0,160$ & 0,873 \\
\hline Bian 2012 & China & 1,049 & 0,748 & 1,471 & 0,277 & 0,782 \\
\hline Bilici 2010 & Turkey & 0,990 & 0,230 & 4,261 & $-0,013$ & 0,989 \\
\hline Chen 2014 & China & 1,024 & 0,883 & 1,188 & 0,314 & 0,754 \\
\hline Choi 2007 & Korea & 0,830 & 0,450 & 1,531 & $-0,597$ & 0,551 \\
\hline de Mat 2007 & the Netherlands & 1,580 & 1,075 & 2,322 & 2,328 & 0,020 \\
\hline Deng 2015 & China & 1,267 & 1,098 & 1,462 & 3,240 & 0,001 \\
\hline Di bartolomeo & Italy & 1,410 & 0,970 & 2,050 & 1,800 & 0,072 \\
\hline Eom 2012 & Korea & 1,030 & 0,510 & 2,080 & 0,082 & 0,934 \\
\hline Fujitani 2012 & Japan & 1,323 & 0,635 & 2,756 & 0,747 & 0,455 \\
\hline Gomez-Martin 2015 & Spain & 1,470 & 1,010 & 2,140 & 2,012 & 0,044 \\
\hline Gong 2005 & US & 1,370 & 0,770 & 2,438 & 1,071 & 0,284 \\
\hline Guo 2013 & China & 1,182 & 1,045 & 1,337 & 2,660 & 0,008 \\
\hline Ha 2013 & Korea & 1,301 & 0,834 & 2,029 & 1,160 & 0,246 \\
\hline Hayashi 2008 & Japan & 1,262 & 0,668 & 2,384 & 0,717 & 0,473 \\
\hline He 2012 & China & 2,470 & 1,166 & 5,232 & 2,361 & 0,018 \\
\hline Hsu 2011 & Taiwan & 1,450 & 1,163 & 1,808 & 3,302 & 0,001 \\
\hline Hu 2015 & China & 1,311 & 0,717 & 2,397 & 0,879 & 0,379 \\
\hline Jang 2010 & Korea & 1,085 & 0,958 & 1,229 & 1,284 & 0,199 \\
\hline Janjigian 2012 & us & 1,330 & 0,930 & 1,902 & 1,562 & 0,118 \\
\hline Jun 2009 & Korea & 1,540 & 0,782 & 3,033 & 1,249 & 0,212 \\
\hline Jung 2011 & Korea & 1,585 & 1,135 & 2,213 & 2,703 & 0,007 \\
\hline Kulig 2010 & Poland & 1,010 & 0,870 & 1,173 & 0,131 & 0,896 \\
\hline Kunz 2012 & US & 1,347 & 1,264 & 1,435 & 9,180 & 0,000 \\
\hline Kawanishi 2000 & Japan & 1,450 & 0,426 & 4,935 & 0,595 & 0,552 \\
\hline Kim KH 2011 & Korea & 1,137 & 0,799 & 1,618 & 0,713 & 0,476 \\
\hline Kim MA 2005 & Korea & 1,106 & 0,866 & 1,413 & 0,807 & 0,420 \\
\hline Koh 2013 & Korea & 1,912 & 1,147 & 3,187 & 2,486 & 0,013 \\
\hline Kurokawa 2015 & Japan & 1,070 & 0,860 & 1,331 & 0,607 & 0,544 \\
\hline Lee HS 2003 & Korea & 1,460 & 0,800 & 2,665 & 1,233 & 0,218 \\
\hline Lee HS 2013 & Korea & 1,790 & 0,894 & 3,584 & 1,644 & 0,100 \\
\hline Lee HW 2015 & Korea & 1,579 & 0,989 & 2,521 & 1,914 & 0,056 \\
\hline Lee JH 2015 & Korea & 2,216 & 0,184 & 26,688 & 0,627 & 0,531 \\
\hline Lee @ 2009 & Korea & 1,810 & 0,380 & 8,621 & 0,745 & 0,456 \\
\hline Marano 2015 & Italy & 1,074 & 0,760 & 1,518 & 0,405 & 0,686 \\
\hline Martinho 2013 & Brazl & 1,560 & 0,740 & 3,289 & 1,169 & 0,243 \\
\hline Matsubara 2008 & Japan & 1,710 & 1,080 & 2,708 & 2,288 & 0,022 \\
\hline Mn 2015 & China & 1,324 & 0,839 & 2,089 & 1,206 & 0,228 \\
\hline Nagashima 2005 & Japan & 1,695 & 1,159 & 2,479 & 2,721 & 0,007 \\
\hline Orditura 2014 & Italy & 1,410 & 0,460 & 4,322 & 0,601 & 0,548 \\
\hline Otsuk 2011 & Japan & 1,100 & 0,460 & 2,630 & 0,214 & 0,830 \\
\hline Park KW 2014 & Korea & 1,165 & 0,843 & 1,610 & 0,925 & 0,355 \\
\hline Park S 2015 & Korea & 1,498 & 1,019 & 2,202 & 2,056 & 0,040 \\
\hline Pinheiro 1999 & the Netherlands & 1,440 & 1,200 & 1,728 & 3,920 & 0,000 \\
\hline Qu 2014 & China & 1,440 & 1,004 & 2,065 & 1,982 & 0,048 \\
\hline Reim 2013 & German & 1,245 & 1,084 & 1,430 & 3,102 & 0,002 \\
\hline Rodriguez Santiago 2005 & Spain & 2,450 & 1,370 & 4,381 & 3,021 & 0,003 \\
\hline Rosa 2014 & Italy & 1,340 & 0,860 & 2,088 & 1,293 & 0,196 \\
\hline Sawak 2012 & Japan & 3,240 & 1,080 & 9,720 & 2,097 & 0,036 \\
\hline Shen 2014 & China & 1,150 & 0,790 & 1,674 & 0,730 & 0,466 \\
\hline Shim HJ 2011 & Korea & 1,020 & 0,620 & 1,678 & 0,078 & 0,938 \\
\hline Shim JH 2014 & Korea & 1,250 & 0,900 & 1,736 & 1,331 & 0,183 \\
\hline Shim JH 2014 & US & 1,250 & 0,830 & 1,883 & 1,068 & 0,285 \\
\hline Shimoyama 2003 & Japan & 5,800 & 1,500 & 22,427 & 2,548 & 0,011 \\
\hline Shinmura 2014 & Japan & 1,662 & 0,871 & 3,171 & 1,541 & 0,123 \\
\hline Sierra 2003 & Spain & 2,780 & 1,470 & 5,257 & 3,145 & 0,002 \\
\hline Stiekema 2013 & the Net & 2317 & 1,188 & 4,519 & 2,465 & 0,014 \\
\hline Stiekema 2015 & the Netherlands & 1,310 & 1,030 & 1,666 & 2,201 & 0,028 \\
\hline Sun 2015 & China & 1,574 & 1,081 & 2,292 & 2,366 & 0,018 \\
\hline Takashima 2014 & Japan & 1,030 & 0,800 & 1,326 & 0,229 & 0,819 \\
\hline Tan 2011 & Vanious & 0,810 & 0,500 & 1,312 & $-0,856$ & 0,392 \\
\hline Verlato 2015 & Italy & 1,910 & 1,090 & 3,347 & 2,261 & 0,024 \\
\hline Wang BB 2011 & Korea & 1,131 & 1,012 & 1,264 & 2,170 & 0,030 \\
\hline Wang L 2003 & us & 0,900 & 0,500 & 1,620 & $-0,351$ & 0,725 \\
\hline Wang XW 201 & China & 1,152 & 0,897 & 1,479 & 1,108 & 0,268 \\
\hline Wu CW 2006 & Taiwan & 1,200 & 0,800 & 1,800 & 0,881 & 0,378 \\
\hline Wu $\times 2010$ & China & 1,036 & 0,786 & 1,366 & 0,251 & 0,802 \\
\hline Xu 2012 & China & 1,181 & 0,945 & 1,476 & 1,463 & 0,144 \\
\hline Yao 2004 & us & 0,780 & 0,360 & 1,690 & $-0,630$ & 0,529 \\
\hline Ye training cohor & Vanious & 1,110 & 0,630 & 1,956 & 0,361 & 0,718 \\
\hline Ye testing cohort 2013 & Vanous & 0,980 & 0,750 & 1,281 & $-0,148$ & 0,882 \\
\hline Ye validation cohort 2013 & Various & 0,680 & 0,490 & 0,944 & $-2,307$ & 0,021 \\
\hline & & 1,231 & 1,173 & 1,292 & 8,436 & 0,000 \\
\hline
\end{tabular}

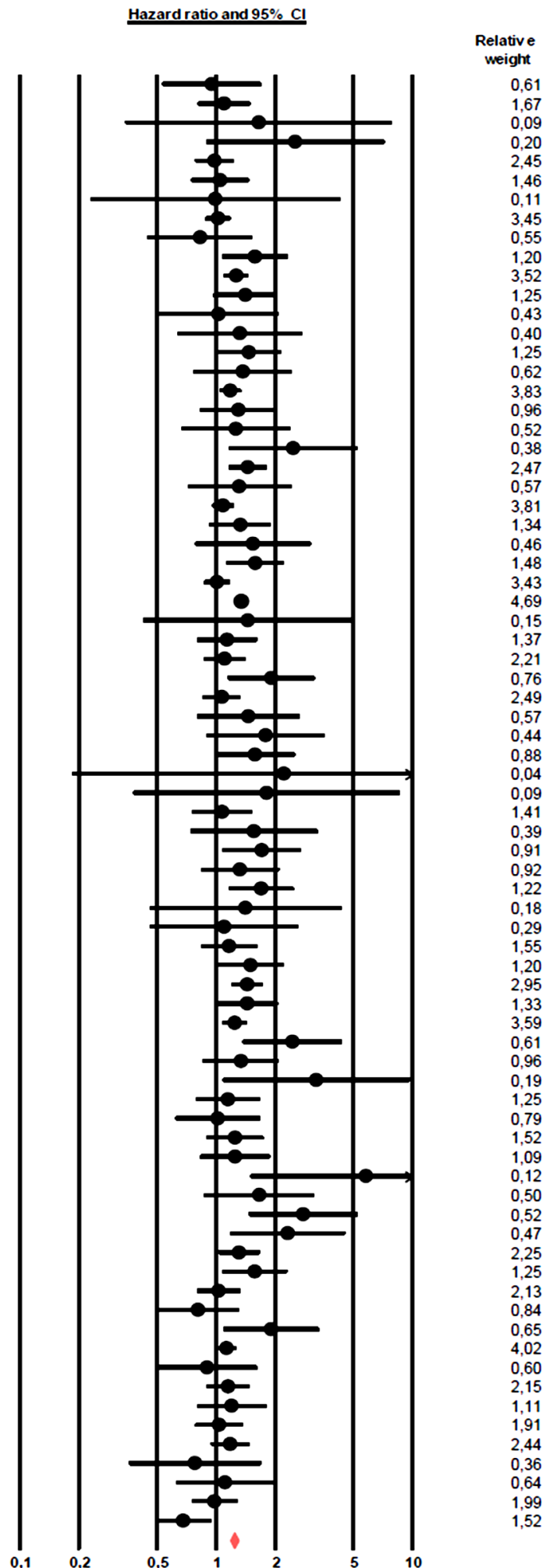

Figure 2 Meta-analysis (forest plot) of 73 studies assessing overall survival of diffuse vs intestinal histology in gastric cancer. 


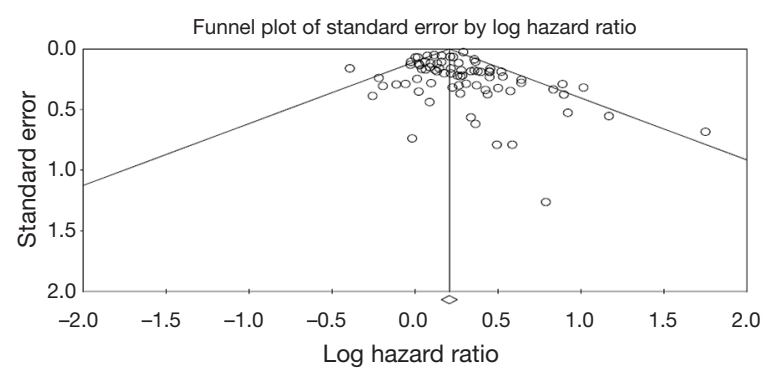

Figure 3 Funnel plot for publication bias (all studies included) of overall survival meta-analysis.

effect model).

The combined HR according to the stage of disease (stage I-III in all tumors $v s$. stage IV disease only) was statistically significant. In fact, a poorer prognosis was observed for both stage I-III and more advanced stages GCs ( $\mathrm{n}=25$ vs. $\mathrm{n}=7$ studies) with diffuse histology (HR 1.21;95\% CI, $1.12-1.3 ; \mathrm{P}<0.0001$ vs. HR 1.25; 95\% CI, $1.04-1.5 ; \mathrm{P}=0.014$ according to random effect model).

In patients exposed to systemic therapy (either for early or advanced disease), the results were similar, with diffuse histology associated with adverse prognosis (HR 1.27; 95\% CI, 1.17-1.37; $\mathrm{P}<0.0001)$. Similar results were observed in studies that not included patients treated with systemic therapy (HR 1.15; 95\% CI, 1.07-1.24; $\mathrm{P}<0.0001$ according to random effect model).

\section{Publication bias}

Both Begg's and Egger's test were significant for publication bias (Figure 3). Given the publication bias observed, we calculated the Trim-and-Fill-adjusted analysis. With this analysis, 16 missing studies based on a random effects model (according to trim and fill method), put to the left side of the mean effect, are calculated for a final HR 1.18 (95\% CI, 1.12-1.24). Finally, the overall result remains unchanged after the one-study-removed procedure, so no dominant study was included.

\section{Discussion}

According to Lauren's classification, GC is categorized as intestinal- and diffuse types (5). Although the Lauren classification system was developed in 1965 , it is still widely accepted and employed by pathologists and oncologist, and represents a simple, reproducible and robust classification approach. Intestinal-type GC is more prevalent in men and older people and is associated with chronic inflammation: as a consequence of Helicobacter Pylori-related atrophic gastritis in the antrum, and as a result of reflux in the gastroesophageal junction. Diffusetype GC is more prevalent in younger people and women, with the absence of a pathogenetic role of inflammation and strong relationship with cell adhesion dysfunctioneven as part of hereditary syndromes in germline $C D H 1$ mutated patients. Clinically, the two histotypes of GC have a different pattern of metastatic spread, with more frequent peritoneal involvement in diffuse cancers (84). Currently, the management of patients with GC is mostly dependent on prognostic assessment based on clinical and pathological stage, while histology still needs to be validated as a prognostic or even predictive factor in patients with GC. As a consequence, treatment algorithms and clinical trials have not been tailored on histotype yet.

In this meta-analysis, we explored whether histology, according to Lauren classification, retains an independent prognostic significance in GC. To our knowledge, this is the first meta-analysis to address this issue. The final pooled analysis showed that diffuse histology, as literature data previously suggested, is confirmed as an independent prognostic factor in multivariate analysis in more than 60,000 patients with resected, localized or advanced GC. In the global population, the risk of death was increased by $23 \%$, and this increased risk was not altered by race, stage (locally advanced $v s$. metastatic) and exposure to chemotherapy. As for now, this represents the most updated systematic on this topic. Liu et al. (7), previously, conducted a meta-analysis examining the survival outcomes among patients with diffuse $v s$. intestinal histology. They found a better 5 -year OS for patients treated with surgery compared with radiotherapy. A major limitation of their study was that they used adjusted and unadjusted odds ratios that do not take into account adjustment for common clinicopathological variables as our paper did.

In patients with GC, the clinical experience suggests a significant variability of outcomes and responsiveness to treatments. The heterogeneity of GC is related to several factors such as epidemiology, pathogenesis, and disease biology. Prognostic and predictive factors beyond disease stage $(3,4)$ are clearly needed, and histotype could be proposed as a surrogate marker of disease biology. A 3-group classification was previously proposed according to histology and tumor site, namely "proximal non-diffuse", "diffuse", and "distal non-diffuse" types $(85,86)$. It was shown that the subtypes have distinct gene expression profiles. Moreover, 
the TCGA study showed the presence of four genomic subtypes [namely, EBV-positive, microsatellite instable, Genome Stable and Chromosomal Instability (87)]. It must be pointed out that microsatellite instable GC is mainly represented by non-diffuse distal cancers while genome stable by intestinal-type ones and chromosomal instability by diffuse-type ones. Thus, there seems to be a good correlation between histology and biology within the TGCA dataset.

The clinical relevance of these data will hopefully allow the distinction in managing each subtype separately. While increasing our knowledge of biological heterogeneity of GC, the goal is to use the distinct biologic subtypes as prognostic and predictive biomarkers to improve patients' management and outcome. However, limited work has been done to create a consensus about the several published subtypes, and their clinical applicability is still difficult due to limited widespread of technologies and costs. Some tools are nowadays implemented for estimating patients' outcome, such as nomograms. One example in GC is the nomogram developed by Kattan et al. (88), where the predictions were based on the following established prognostic factors: patient's age and gender, tumor size, depth of tumor invasion, percentage of positive and negative nodes and, notably, tumor primary location and histology. Based on these data and our results, histology may be already used as a simple, costless and easy stratification factor in clinical trials for patients with homogeneous disease stage. It may be also used with predictive purposes when assessing the efficacy of newer drugs. Notably, it was already shown that HER-2 amplification is mostly found in intestinal-type and proximal cancers (89), while FGFR2 amplification is typical of diffuse tumors (90), and even antiangiogenic drugs may be more effective in intestinal-type GC (91).

A limitation of this review, as with any review or metaanalysis, is publication bias. Publication bias occurs when negative results (negative histology results in our case), which are often not published, are excluded. Analyses of efficacy by histologic subtype may not be reported for several reasons: the histology data were not collected; analyses were not performed because the study was inadequately powered or because historical evidence suggested such analyses were not important; analyses were performed but results were negative (and/or inconsistent across other endpoints) and therefore not reported; or results of analyses were positive but not reported because it was unclear how to interpret the findings. However, heterogeneity was moderate $\left(\mathrm{I}^{2}=38 \%\right)$, and it has been taken in account through a random effect model analysis. Also, even if publication bias was somewhat significant with Begg's and Egger's tests, the leave-one-out procedure, excluded any "dominant" study. Furthermore, sensitivity analysis adjusting for race, use of systemic therapy or stage did not modify the overall result substantially. Finally, the trim-and-fill procedure found that putting 16 asymmetric studies on the left of the mean effect of the funnel plot; the final results remained substantially unaltered. A second limitation is the use of the Lauren instead World Health Organization classification, that split adenocarcinomas in papillary, tubular mucinous, poorly cohesive and mixed forms. Only two papers included into classification of diffuse types poorly cohesive or signet ring cases, and aim of paper was the validation of prognostic significance of Lauren's subtypes, that is still controversial.

On the contrary, major strengths of this paper are the comprehensive search strategy, careful selection of studies, the attempt of subgroup analyses, and the use of survival outcome that consider HRs adjusted for common confounders.

Many biomarkers are being evaluated to establish prognostic or predictive factors in GC, and several have been identified for their potential key role, but their clinical use remains controversial. In this scenario, the prognostic role of histology seems to confirm a valid prognostic indicator and will play a significant role in future clinical trials.

\section{Acknowledgements}

None.

\section{Footnote}

Conflicts of Interest: The authors have no conflicts of interest to declare.

\section{References}

1. Siegel R, Ma J, Zou Z, et al. Cancer statistics, 2014. CA Cancer J Clin 2014;64:9-29.

2. Sobin LH, Gospodarowicz MK, Wittekind C. TNM classification of malignant tumours. 7th ed. New York, NY: Wiley-Blackwell, 2009.

3. Miceli R, Tomasello G, Bregni G, et al. Adjuvant chemotherapy for gastric cancer: current evidence and future challenges. World J Gastroenterol 2014;20:4516-25. 
4. Pietrantonio F, De Braud F, Da Prat V, et al. A review on biomarkers for prediction of treatment outcome in gastric cancer. Anticancer Res 2013;33:1257-66.

5. Lauren P. The two histological main types of gastric carcinoma: diffuse and so-called intestinal-type carcinoma. an attempt at a histo-clinical classification. Acta Pathol Microbiol Scand 1965;64:31-49.

6. Bosman FT, Carniero F, Hruban RH, et al. WHO Classification of Tumours of the Digestive System. 4th ed. Lyon: IARC, 2010.

7. Liu L, Wang ZW, Ji J, et al. A cohort study and metaanalysis between histopathological classification and prognosis of gastric carcinoma. Anticancer Agents Med Chem 2013;13:227-34.

8. Begg CB, Mazumdar M. Operating characteristics of a rank correlation test for publication bias. Biometrics 1994;50:1088-101.

9. Egger M, Davey Smith G, Schneider M, et al. Bias in meta-analysis detected by a simple, graphical test. BMJ 1997;315:629-34.

10. Duval S, Tweedie R. Trim and fill: A simple funnel-plotbased method of testing and adjusting for publication bias in meta-analysis. Biometrics 2000;56:455-63.

11. An JY, Baik YH, Choi MG, et al. The prognosis of gastric cardia cancer after R0 resection. Am J Surg 2010;199:725-9.

12. Atmaca A, Werner D, Pauligk C, et al. The prognostic impact of epidermal growth factor receptor in patients with metastatic gastric cancer. BMC Cancer 2012;12:524.

13. Ben Ayed-Guerfali D, Benhaj K, Khabir A, et al. Hypermethylation of tumor-related genes in Tunisian patients with gastric carcinoma: clinical and biological significance. J Surg Oncol 2011;103:687-94.

14. Bani-Hani KE, Almasri NM, Khader YS, et al. Combined evaluation of expressions of cyclin $\mathrm{E}$ and $\mathrm{p} 53$ proteins as prognostic factors for patients with gastric cancer. Clin Cancer Res 2005;11:1447-53.

15. Becker K, Reim D, Novotny A, et al. Proposal for a multifactorial prognostic score that accurately classifies 3 groups of gastric carcinoma patients with different outcomes after neoadjuvant chemotherapy and surgery. Ann Surg 2012;256:1002-7.

16. Bian Y, Wang L, Lu H, et al. Downregulation of tumor suppressor QKI in gastric cancer and its implication in cancer prognosis. Biochem Biophys Res Commun 2012;422:187-93.

17. Bilici A, Seker M, Ustaalioglu BB, et al. Prognostic significance of perineural invasion in patients with gastric cancer who underwent curative resection. Ann Surg Oncol
2010;17:2037-44.

18. Chen L, Shi Y, Yuan J, et al. Evaluation of docetaxeland oxaliplatin-based adjuvant chemotherapy in postgastrectomy gastric cancer patients reveals obvious survival benefits in docetaxel-treated mixed signet ring cell carcinoma patients. Med Oncol 2014;31:159.

19. Choi SC, Yoon SR, Park YP, et al. Expression of NDRG2 is related to tumor progression and survival of gastric cancer patients through Fas-mediated cell death. Exp Mol Med 2007;39:705-14.

20. de Maat MF, van de Velde CJ, Umetani N, et al. Epigenetic silencing of cyclooxygenase-2 affects clinical outcome in gastric cancer. J Clin Oncol 2007;25:4887-94.

21. Deng J, Zhang R, Pan Y, et al. Tumor size as a recommendable variable for accuracy of the prognostic prediction of gastric cancer: a retrospective analysis of 1,521 patients. Ann Surg Oncol 2015;22:565-72.

22. Di Bartolomeo M, Pietrantonio F, Pellegrinelli A, et al. Osteopontin, E-cadherin, and $\beta$-catenin expression as prognostic biomarkers in patients with radically resected gastric cancer. Gastric Cancer 2016;19:412-20.

23. Eom BW, Kim YW, Lee SE, et al. Survival and surgical outcomes after laparoscopy-assisted total gastrectomy for gastric cancer: case-control study. Surg Endosc 2012;26:3273-81.

24. Fujitani K, Mano M, Hirao M, et al. Posttherapy nodal status, not graded histologic response, predicts survival after neoadjuvant chemotherapy for advanced gastric cancer. Ann Surg Oncol 2012;19:1936-43.

25. Gómez-Martin C, Garralda E, Echarri MJ, et al. HER2/ neu testing for anti-HER2-based therapies in patients with unresectable and/or metastatic gastric cancer. J Clin Pathol 2012;65:751-7.

26. Gong W, Wang L, Yao JC, et al. Expression of activated signal transducer and activator of transcription 3 predicts expression of vascular endothelial growth factor in and angiogenic phenotype of human gastric cancer. Clin Cancer Res 2005;11:1386-93.

27. Guo $\mathrm{P}, \mathrm{Li} Y, \mathrm{Zhu} Z$, et al. Prognostic value of tumor size in gastric cancer: an analysis of 2,379 patients. Tumour Biol 2013;34:1027-35.

28. Ha SY, Lee J, Kang SY, et al. MET overexpression assessed by new interpretation method predicts gene amplification and poor survival in advanced gastric carcinomas. Mod Pathol 2013;26:1632-41.

29. Hayashi $M$, Inokuchi $M$, Takagi $Y$, et al. High expression of HER3 is associated with a decreased survival in gastric cancer. Clin Cancer Res 2008;14:7843-9. 
30. He H, Chen W, Wang X, et al. Snail is an independent prognostic predictor for progression and patient survival of gastric cancer. Cancer Sci 2012;103:1296-303.

31. Hsu JT, Chen TC, Tseng JH, et al. Impact of HER-2 overexpression/amplification on the prognosis of gastric cancer patients undergoing resection: a single-center study of 1,036 patients. Oncologist 2011;16:1706-13.

32. Hu M, Li K, Maskey N, et al. Overexpression of the chemokine receptor CXCR3 and its correlation with favorable prognosis in gastric cancer. Hum Pathol 2015;46:1872-80.

33. Jang JH, Beron RI, Ahn HS, et al. Clinicopathological Features of Upper Third Gastric Cancer during a 21Year Period (Single Center Analysis). J Gastric Cancer 2010;10:212-8.

34. Janjigian YY, Werner D, Pauligk C, et al. Prognosis of metastatic gastric and gastroesophageal junction cancer by HER2 status: a European and USA International collaborative analysis. Ann Oncol 2012;23:2656-62.

35. Jun KH, Jung H, Baek JM, et al. Does tumor size have an impact on gastric cancer? A single institute experience. Langenbecks Arch Surg 2009;394:631-5.

36. Jung MR, Park YK, Jeong O, et al. Elevated preoperative neutrophil to lymphocyte ratio predicts poor survival following resection in late stage gastric cancer. J Surg Oncol 2011;104:504-10.

37. Kulig J, Sierzega M, Kolodziejczyk P, et al. Implications of overweight in gastric cancer: A multicenter study in a Western patient population. Eur J Surg Oncol 2010;36:969-76.

38. Kunz PL, Gubens M, Fisher GA, et al. Long-term survivors of gastric cancer: a California population-based study. J Clin Oncol 2012;30:3507-15.

39. Kawanishi K, Doki Y, Shiozaki H, et al. Correlation between loss of E-cadherin expression and overexpression of autocrine motility factor receptor in association with progression of human gastric cancers. Am J Clin Pathol 2000;113:266-74.

40. Kim KH, Kwon HC, Oh SY, et al. Clinicopathologic significance of ERCC1, thymidylate synthase and glutathione S-transferase P1 expression for advanced gastric cancer patients receiving adjuvant 5-FU and cisplatin chemotherapy. Biomarkers 2011;16:74-82.

41. Kim MA, Lee HS, Yang HK, et al. Clinicopathologic and protein expression differences between cardia carcinoma and noncardia carcinoma of the stomach. Cancer 2005;103:1439-46.

42. Koh YW, Park YS, Ryu MH, et al. Postoperative nodal status and diffuse-type histology are independent prognostic factors in resectable advanced gastric carcinomas after preoperative chemotherapy. Am J Surg Pathol 2013;37:1022-9.

43. Kurokawa Y, Matsuura N, Kimura Y, et al. Multicenter large-scale study of prognostic impact of HER2 expression in patients with resectable gastric cancer. Gastric Cancer 2015;18:691-7.

44. Lee HS, Lee HK, Kim HS, et al. Tumour suppressor gene expression correlates with gastric cancer prognosis. J Pathol 2003;200:39-46.

45. Lee HS, Lee HE, Yang HK, et al. Perigastric tumor deposits in primary gastric cancer: implications for patient prognosis and staging. Ann Surg Oncol 2013;20:1604-13.

46. Lee HW, Park MI, Kim MS, et al. Overexpression of phosphorylated 4E-binding protein 1 and its clinicopathological significances in gastric cancer. Pathol Res Pract 2015;211:298-302.

47. Lee JH, Kim MG, Jung MS, et al. Prognostic significance of lymphovascular invasion in node-negative gastric cancer. World J Surg 2015;39:732-9.

48. Lee OJ, Kim HJ, Kim JR, et al. The prognostic significance of the mucin phenotype of gastric adenocarcinoma and its relationship with histologic classifications. Oncol Rep 2009;21:387-93.

49. Marano L, Boccardi V, Braccio B, et al. Comparison of the 6th and 7th editions of the AJCC/UICC TNM staging system for gastric cancer focusing on the "N" parameterrelated survival: the monoinstitutional NodUs Italian study. World J Surg Oncol 2015;13:215.

50. Martinho O, Simões K, Longatto-Filho A, et al. Absence of RKIP expression is an independent prognostic biomarker for gastric cancer patients. Oncol Rep 2013;29:690-6.

51. Matsubara J, Yamada Y, Hirashima Y, et al. Impact of insulin-like growth factor type 1 receptor, epidermal growth factor receptor, and HER2 expressions on outcomes of patients with gastric cancer. Clin Cancer Res 2008;14:3022-9.

52. Min L, Ruan Y, Shen Z, et al. Overexpression of RasGTPase-activating protein $\mathrm{SH} 3$ domain-binding protein 1 correlates with poor prognosis in gastric cancer patients. Histopathology 2015;67:677-88.

53. Nagashima F, Boku N, Ohtsu A, et al. Biological markers as a predictor for response and prognosis of unresectable gastric cancer patients treated with irinotecan and cisplatin. Jpn J Clin Oncol 2005;35:714-9.

54. Orditura M, Galizia G, Di Martino N, et al. Effect 
of preoperative chemoradiotherapy on outcome of patients with locally advanced esophagogastric junction adenocarcinoma-a pilot study. Curr Oncol 2014;21:125-33.

55. Otsuki S, Inokuchi M, Enjoji M, et al. Vimentin expression is associated with decreased survival in gastric cancer. Oncol Rep 2011;25:1235-42.

56. Park KW, Kim SJ, Oh SY. Clinicopathologic significance of nuclear factor- $\kappa \mathrm{B}$ and vascular endothelial growth factor expression in advanced gastric cancer patients. Oncol Res Treat 2014;37:183-90.

57. Park S, Choi MG, Kim KM, et al. Lymphoepitheliomalike carcinoma: a distinct type of gastric cancer. J Surg Res 2015;194:458-63.

58. Pinheiro PS, van der Heijden LH, Coebergh JW. Unchanged survival of gastric cancer in the southeastern Netherlands since 1982: result of differential trends in incidence according to Laurén type and subsite. Int J Cancer 1999;84:28-32.

59. Qiu M, Zhou Y, Zhang X, et al. Lauren classification combined with HER2 status is a better prognostic factor in Chinese gastric cancer patients. BMC Cancer 2014;14:823.

60. Reim D, Loos M, Vogl F, et al. Prognostic implications of the seventh edition of the international union against cancer classification for patients with gastric cancer: the Western experience of patients treated in a single-center European institution. J Clin Oncol 2013;31:263-71.

61. Rodríguez Santiago JM, Muñoz E, Martí M, et al. Metastatic lymph node ratio as a prognostic factor in gastric cancer. Eur J Surg Oncol 2005;31:59-66.

62. Rosa F, Alfieri S, Tortorelli AP, et al. Trends in clinical features, postoperative outcomes, and long-term survival for gastric cancer: a Western experience with 1,278 patients over 30 years. World J Surg Oncol 2014;12:217.

63. Sawaki A, Ohashi Y, Omuro Y, et al. Efficacy of trastuzumab in Japanese patients with HER2-positive advanced gastric or gastroesophageal junction cancer: a subgroup analysis of the Trastuzumab for Gastric Cancer (ToGA) study. Gastric Cancer 2012;15:313-22.

64. Shen L, Du M, Wang C, et al. Clinical significance of POU5F1P1 rs10505477 polymorphism in Chinese gastric cancer patients receving cisplatin-based chemotherapy after surgical resection. Int J Mol Sci 2014;15:12764-77.

65. Shim HJ, Yun JY, Hwang JE, et al. Prognostic factor analysis of third-line chemotherapy in patients with advanced gastric cancer. Gastric Cancer 2011;14:249-56.

66. Shim JH, Song KY, Jeon HM, et al. Is gastric cancer different in Korea and the United States? Impact of tumor location on prognosis. Ann Surg Oncol 2014;21:2332-9.
67. Shimoyama S, Kaminishi M. Angiogenin in sera as an independent prognostic factor in gastric cancer. J Cancer Res Clin Oncol 2003;129:239-44.

68. Shinmura K, Kiyose S, Nagura K, et al. TNK2 gene amplification is a novel predictor of a poor prognosis in patients with gastric cancer. J Surg Oncol 2014;109:189-97.

69. Sierra A, Regueira FM, Hernández-Lizoáin JL, et al. Role of the extended lymphadenectomy in gastric cancer surgery: experience in a single institution. Ann Surg Oncol 2003;10:219-26.

70. Stiekema J, Cats A, Kuijpers A, et al. Surgical treatment results of intestinal and diffuse type gastric cancer. Implications for a differentiated therapeutic approach? Eur J Surg Oncol 2013;39:686-93.

71. Stiekema J, Trip AK, Jansen EP, et al. Does adjuvant chemoradiotherapy improve the prognosis of gastric cancer after an $\mathrm{r} 1$ resection? Results from a dutch cohort study. Ann Surg Oncol 2015;22:581-8.

72. Sun XR, Sun Z, Zhu Z, et al. Expression of pyruvate dehydrogenase is an independent prognostic marker in gastric cancer. World J Gastroenterol 2015;21:5336-44.

73. Takashima A, Boku N, Kato K, et al. Survival prolongation after treatment failure of first-line chemotherapy in patients with advanced gastric cancer: combined analysis of the Japan Clinical Oncology group trials JCOG9205 and JCOG9912. Gastric Cancer 2014;17:522-8.

74. Tan IB, Ivanova T, Lim KH, et al. Intrinsic subtypes of gastric cancer, based on gene expression pattern, predict survival and respond differently to chemotherapy. Gastroenterology 2011;141:476-85, 485.e1-11.

75. Verlato G, Marrelli D, Accordini S, et al. Short-term and long-term risk factors in gastric cancer. World J Gastroenterol 2015;21:6434-43.

76. Wang BB, Liu CG, Lu P, et al. Log-normal censored regression model detecting prognostic factors in gastric cancer: a study of 3018 cases. World J Gastroenterol 2011;17:2867-72.

77. Wang L, Wei D, Huang S, et al. Transcription factor Sp1 expression is a significant predictor of survival in human gastric cancer. Clin Cancer Res 2003 9:6371-80.

78. Wang X, Huang CJ, Yu GZ, et al. Expression of group IIA phospholipase A2 is an independent predictor of favorable outcome for patients with gastric cancer. Hum Pathol 2013;44:2020-7.

79. Wu CW, Hsiung CA, Lo SS, et al. Nodal dissection for patients with gastric cancer: a randomised controlled trial. Lancet Oncol 2006;7:309-15.

80. Wu X, Zeng Z, Chen B, et al. Association between 
polymorphisms in interleukin-17A and interleukin$17 \mathrm{~F}$ genes and risks of gastric cancer. Int J Cancer 2010;127:86-92.

81. Xu Z, Zhu H, Luk JM, et al. Clinical significance of SOD2 and GSTP1 gene polymorphisms in Chinese patients with gastric cancer. Cancer 2012;118:5489-96.

82. Yao JC, Wang L, Wei D, et al. Association between expression of transcription factor Sp1 and increased vascular endothelial growth factor expression, advanced stage, and poor survival in patients with resected gastric cancer. Clin Cancer Res 2004;10:4109-17.

83. Ye Y, Li X, Yang J, et al. MDM2 is a useful prognostic biomarker for resectable gastric cancer. Cancer Sci 2013;104:590-8.

84. Marrelli D, Roviello F, de Manzoni G, et al. Different patterns of recurrence in gastric cancer depending on Lauren's histological type: longitudinal study. World J Surg 2002;26:1160-5.

85. Bittoni A, Scartozzi M, Giampieri R, et al. Clinical evidence for three distinct gastric cancer subtypes: time for a new approach. PLoS One 2013;8:e78544.

Cite this article as: Petrelli F, Berenato R, Turati L, Mennitto A, Steccanella F, Caporale M, Dallera P, de Braud F, Pezzica E, Di Bartolomeo M, Sgroi G, Mazzaferro V, Pietrantonio F, Barni S. Prognostic value of diffuse versus intestinal histotype in patients with gastric cancer: a systematic review and metaanalysis. J Gastrointest Oncol 2017;8(1):148-163. doi: 10.21037/ jgo.2017.01.10
86. Shah MA, Khanin R, Tang L, et al. Molecular classification of gastric cancer: a new paradigm. Clin Cancer Res 2011;17:2693-701.

87. Cancer Genome Atlas Research Network.. Comprehensive molecular characterization of gastric adenocarcinoma. Nature 2014;513:202-9.

88. Kattan MW, Karpeh MS, Mazumdar M, et al. Postoperative nomogram for disease-specific survival after an R0 resection for gastric carcinoma. J Clin Oncol 2003;21:3647-50.

89. Van Cutsem E, Bang YJ, Feng-Yi F, et al. HER2 screening data from ToGA: targeting HER2 in gastric and gastroesophageal junction cancer. Gastric Cancer 2015;18:476-84.

90. Park YS, Na YS, Ryu MH, et al. FGFR2 Assessment in Gastric Cancer Using Quantitative Real-Time Polymerase Chain Reaction, Fluorescent In Situ Hybridization, and Immunohistochemistry. Am J Clin Pathol 2015;143:865-72.

91. Roviello G, Petrioli R, Marano L, et al. Angiogenesis inhibitors in gastric and gastroesophageal junction cancer. Gastric Cancer 2016;19:31-41. 